\title{
AN ORIGINAL INTERCONNECTION TECHNIQUE FOR AN ELECTRONIC PAYMENT CARD*
}

\author{
M. MONNIER and M. MONNERAYE \\ Laboratoires d'Electronique et de Physique Appliquée 3, avenue Descartes, 94450 Limeil-Brévannes, \\ France
}

(Received November 12, 1981; in final form March 3, 1982)

This paper intends to illustrate, through a practical application, the possibilities of LEP foil flexible circuitry for mounting and interconnecting integrated circuits. This technique results in a high density packaging which is used here for the integration of two components, a microprocessor and a memory, in an electronic payment card.

\section{INTRODUCTION}

For about two years, newspapers have published many articles dealing with memory cards. Numerous applications of such cards have been cited, some of them are certainly of interest, but for different reasons only the electronic payment card seems to be in a real development state today.

This application, fortunately or unfortunately, involves all the basic functions which can be realized electronically in such cards: secure identification, access key, portable memory and encryption. Moreover for psychological and also economical reasons this new electronic card has to be compatible with all the existing features of the well-known magnetic plastic credit card. It means clearly that this card has to be an ISO standard one.

These conditions being stated, we will discuss now the influence of each of them in order to make the best choice of the most suitable technology.

\section{THE ELECTRONIC PAYMENT SYSTEM}

A project involving French banks and French telecommunications administration starts as a public experiment at the beginning of 1982. This electronic system allows the transfer of money between private customers and retailers without using paper like notes, cheques, or credit vouchers. The electronic card realizes the transactions in a real offline system without any use of external computer or network. For obvious security reasons, all the intelligence must be located in the card and not in the retailers terminal which could be more easily falsified with a view to using it fraudulently. In fact, in the Phillips Card System, this active payment card is used as an electronic cheque book. At the point of sale, payment transactions will be performed without any connection to the bank but with a number of security protections:

(i) mutual authentification of card and machine

(ii) use of a PIN (Personal Identification Number) code protection of the customer against loss or theft of his card

*Paper presented at the Technical Sessions Programme of Productronica, Munich, November, 1981. 
(iii) automatic search through a "hot card" file

(iv) revolving expenditure limit fixed by the bank and controlled by the card

(v) calculation of the remaining buying power.

Moreover, all transactions being dated and indelibly recorded in the card memory, must later on be read-out. Each card must have a capacity of 150 to 200 transactions.

At the moment this can only be performed using two electronic components:

(a) one 8 bit microprocessor,

(b) one $16 \mathrm{Kbit}$ non volatile memory,

or, in terms of dimensions, using two chips of about $4 \times 5 \mathrm{~mm}$ in size, $0.4 \mathrm{~mm}$ thick, with about 25 pads each to be interconnected with each other, the complete system connecting to the outside world through 8 sread-write contacts.

\section{- FROM THE EXISTING PLASTIC MAGNETIC CREDIT CARD TO THE ELECTRONIC CARD}

The magnetic card is described by ISO standard 2894. Additional magnetic strips, Transac 2 and 3 are required in some automatic cash dispensers (figure 1).

It consists of a rectangular PVC sheet with a total thickness of $0.76 \mathrm{~mm}$. The lower part is devoted to the embossed marks which can be read with the so-called 'Flat Iron' or 'Smash reader'. The upper part of the front side is occupied by other identification marks like the photograph of the owner, signature . . . etc ..., the magnetic strips being localized on the rear-side. The area remaining free for receiving in a cavity the electronic components is restricted to a very narrow one. Taking into account the problems of bendability of the card, it is necessary to remove the IC's further off the area of maximum radius of curvature and therefore, reducing as much as possible the dimensions of this cavity, to locate it near the periphery of the card. Such localization minimized either the effects of curvature or the stresses due to the pressure of the magnetic reading heads in the automatic cash dispensers or other magnetic systems.

All these requirements determine the specifications of the "chips carrier" suitable in such a card. This substrate has to be:

(i) as thin and small as possible,

(ii) flexible,

(iii) able to realize the mounting of and the interconnections between two active chips,

(iv) able to provide external contacts

(v) compatible with the usual lamination techniques of PVC.

Such are the reasons why after examining hybrid techniques and systems like wire bonding and PC boards, we propose a new interconnection technology.

\section{THE LEP CARD PROJECT}

Starting from the technique already described ${ }^{1}$ of a double-sided flexible circuitry on polyimide foil in which interconnection is achieved through metallized holes, ${ }^{2}$ an electronic payment card has been developed. It includes an 8021 (28 pins) microprocessor which is combined with a 2716 (24 pins) memory. Both chips are mounted on and fully interconnected through a $25 \mu \mathrm{m}$ thick polyimide circuit film, which also provides the 8 write-read contacts. The $20 \times 25 \mathrm{~mm}^{2}$ micromodule is embedded in the PVC card. 


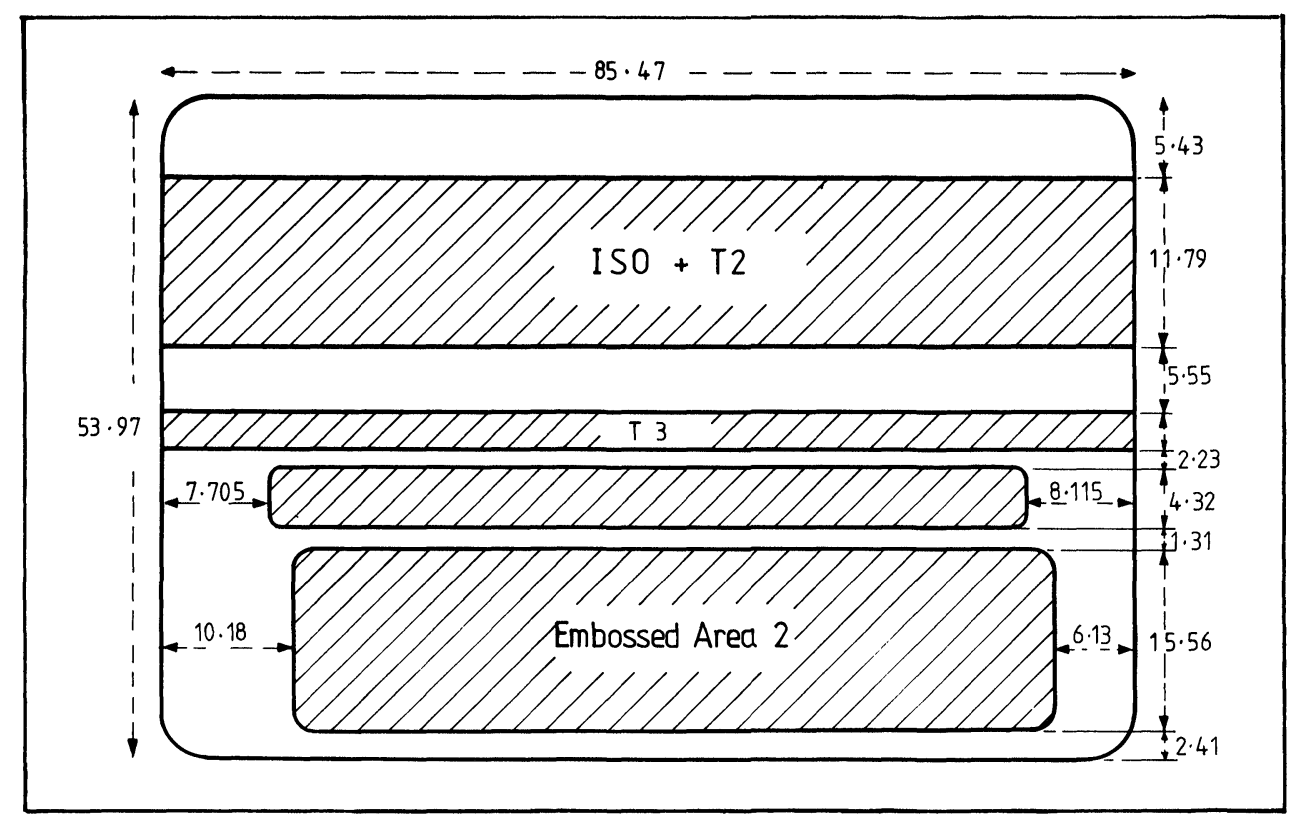

FIGURE 1 Dimensions required of Electronic Payment Card.

\section{THE POLYIMIDE CIRCUITRY}

The production of the interconnected double sided circuit involves only chemical and electrochemical sequences. The processing of the $35 \mathrm{~mm}$ film of kapton (Du Pont de Nemours trademark) includes the following steps:

(i) pre-etching-degreasing of the film

(ii) chemical milling of the holes through a photoresist-etching process. Holes are used for the interconnection of the conductors, but holes which will be used for maintaining the micromodule in the PVC are also drilled in this sequence

(iii) stripping of the photoresist

(iv) carefully controlled electroless nickel plating, about $2000, \AA$ both sides and the through-holes ("vias") are then plated;

(v) drying of the plated film, double side rolling of a dry film photoresist;

(vi) photoprocessing of the resist, followed by electrochemical growing of the interconnection pattern using electroless Nickel as the conductive layer. Perforations of the film and reference marks are used for the perfect superposition of the conductors and their interconnecting metallized holes;

(vii) stripping of the resist, etching away of the unwanted Nickel plating.

Due to the electrochemical process involved for growing the conductive pattern from the Nickel deposit, any kind of conductor could be obtained. The same holds for any kind of finishing. For economical reasons, we recommend copper conductors with a flash of gold on outside contacts, a tin-lead finishing being required if the mounting of active chips by reflow soldering is chosen. Other possibilities are shown in table I

At the end of this sequence, the interconnection circuit including 8 contacts is ready for chips mounting (Figure 2). 
TABLE I

Possible methods of chips mounting

\begin{tabular}{|c|c|c|c|c|}
\hline \multirow{2}{*}{$\begin{array}{l}\text { Kapton } \\
\text { circuit } \\
\text { finishing }\end{array}$} & \multirow{2}{*}{$\begin{array}{r}\text { Metallization } \\
\text { of the } \\
\text { pads }\end{array}$} & \multicolumn{2}{|c|}{ Bumps } & \multirow{2}{*}{$\begin{array}{l}\text { Thin-film } \\
\text { metallization } \\
(\mathrm{Cr}-\mathrm{Ni}-\mathrm{Au})\end{array}$} \\
\hline & & Gold & Tin-lead & \\
\hline Tin lead & & gl & r.s. or gl. & r.s. or s.p.gl. \\
\hline Tin & & r.s. & r.s. & r.s. or s.p.gl. \\
\hline Gold & & gl. & r.s. & s.p.gl. \\
\hline $\begin{array}{l}\text { r.s. } \\
\text { g.l. } \\
\text { s.p.gl. }\end{array}$ & \multicolumn{4}{|c|}{$\begin{array}{l}=\text { reflow soldering } \\
=\text { glueing (bumps dipped in the adhesive) } \\
=\text { glueing (screen-printed dots of adhesive) }\end{array}$} \\
\hline \multicolumn{5}{|c|}{ Note: if soldering is possible, forget glueing! } \\
\hline
\end{tabular}

\section{THE MOUNTING OF THE CHIPS}

Table I (see page 0 ) summarizes some of the possibilites which are offered to the hybridist for mounting the active chips on the kapton circuit. This is a consequence of both the different finishes which are offered by the circuit processing and the metallization chosen for the pads of the chips. ${ }^{3}$

One has to remember one important feature of the kapton circuit: every mounting pad on the circuit is located at the reverse of its own conductor and the connecting hole actually helps the location of bumps-on-chip, and for the localization of the mounting medium (adhesive, solder).

From the different possibilities offered in Table I, the "flat metallization" reflow soldering is a typical LEP project. In this method, the mounting of the chips is performed using the well-known equipment developed for TAB gang-bonding, the whole of the pads being bonded in one reflowing sequence only.

At this step the active micromodule resembles a postage stamp carrying the memory and microprocessor chips.

\section{- THE PACKAGING OF THE MICROMODULE IN THE CARD}

The structure of the electronic card has been shown in Figure 2. Two openings for locating the chips are made in the PVC holder foil of the card. This core also carries the required

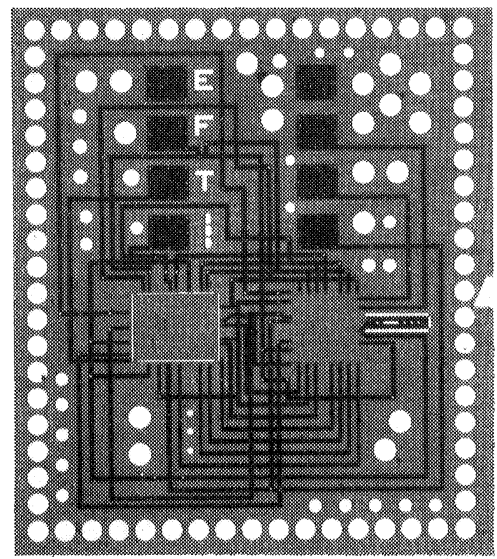

FIGURE 2 The double sided interconnection circuit as seen in transmission. 
magnetic strips, owner's photograph, etc. . . The core is colaminated between two sheets of PVC, the top one leaving free the write-read contacts (Figure 3). In their cavities, the chips are encapsulated in a protective elastic coating. When the top PVC sheet is rolled on to the core, the laminating temperature is chosen so as to permit a gentle flowing of the plastic through the holes provided in the circuit foil (Figure 3). This achieves the "anchoring" of the micromodule at the right location (Figure 4). In fact, the kapton foil does not glue to the PVC, and the area receiving the ICs is virtually floating freely inside the card, which prevents any break in the connections when the card bends. This is one of the main requirements specified by the bankers.

Figure 5 shows a complete card, and Figure 6 shows such a card being offered up to a terminal. A typical transaction situation is demonstrated in Figure 7.

\section{CONCLUSION}

In this paper we have discussed a prototype of an electronic payment card (Figure 5) including a memory and a microprocessor which could be activated, through 8 output

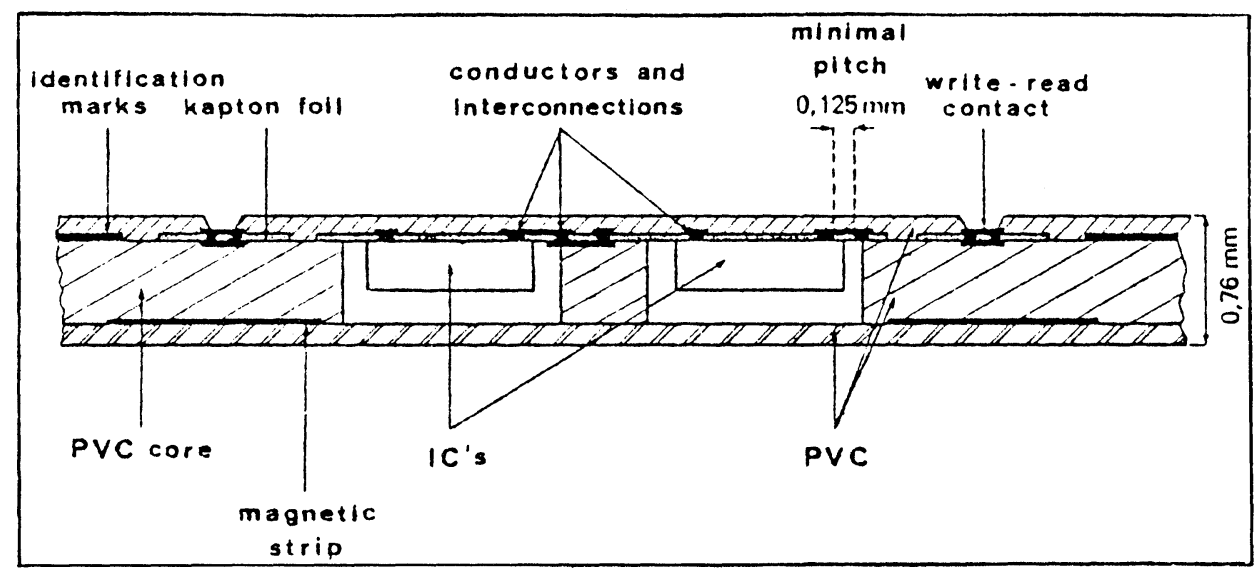

FIGURE 3 Diagrammatic section through card.

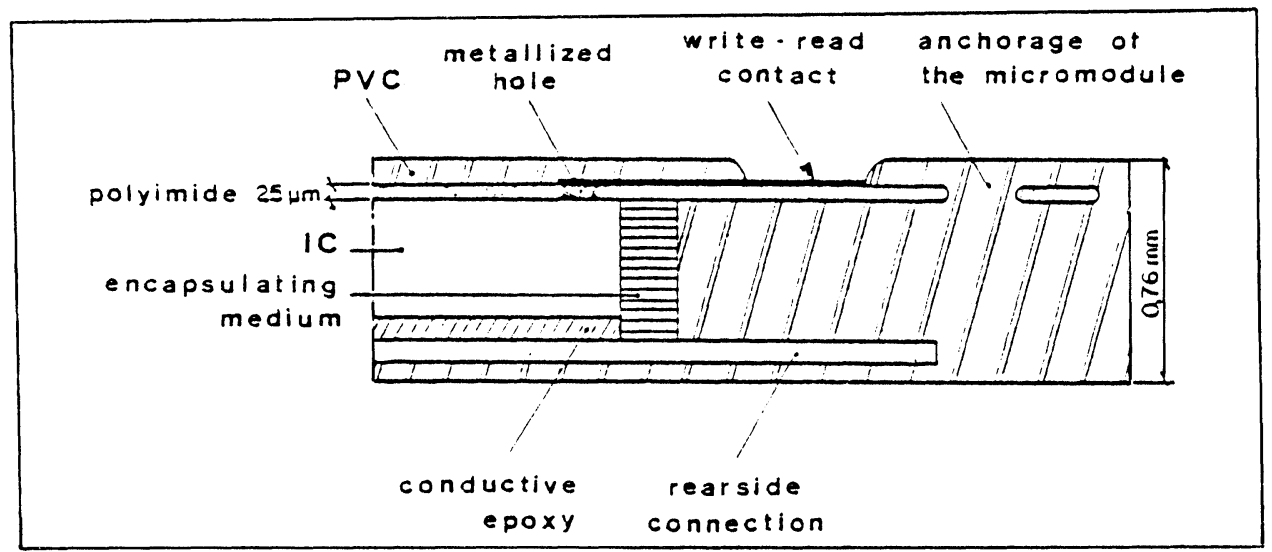

FIGURE 4 Diagrammatic section showing the anchorage of the micromodule. 


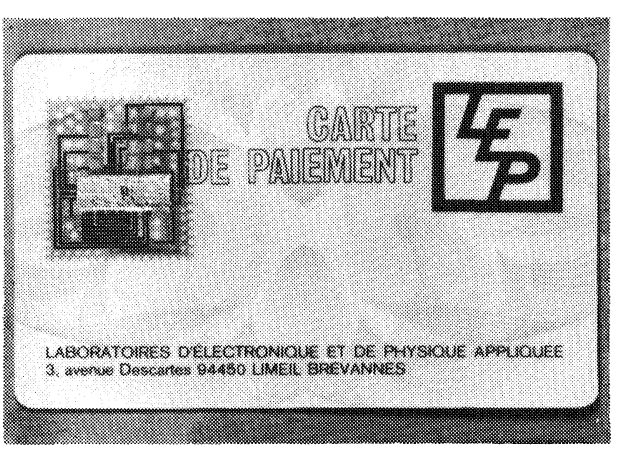

FIGURE 5 Prototype of the Electronic Payment Card.

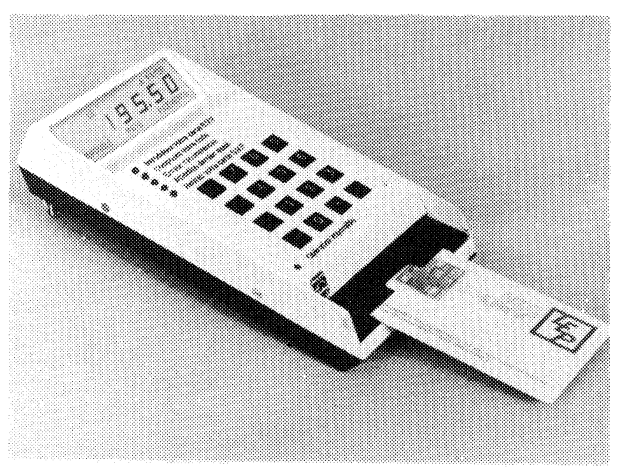

FIGURE 6 Typical card terminal.

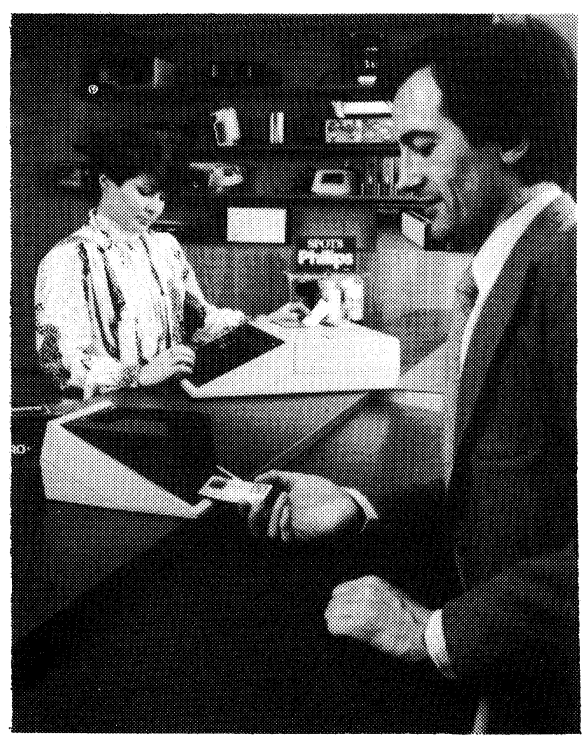

FIGURE 7 Typical transaction arrangements. 
contacts, by a terminal module. Although incorporating these two active chips, this card retains all of the required properties $(0.76 \mathrm{~mm}$ thickness, bendability, et. .) and facilities (magnetic strips, embossing, photography, signature, etc. . .). This result is obtained owing to the packaging of the active chips on a kapton foil circuitry which is incorporated into the card.

\section{ACKNOWLEDGEMENTS}

We wish to acknowledge the effective technical assistance given by Laurence Rosado and Roger Jougla.

\section{REFERENCES}

1. M. Monnier, Une nouvelle technique de montage et d'interconnexion de composants, Acta Electronica, 21, 4, pp 333-341 (1978).

2. B. Cassanhiol, M. Monnier, Brevet français 2320361 (filed 1975).

3. M. Monnier, M. Monneraye, C. Foucher, Brevet français 2402996 (filed 1977).

M. Monnier, M. Monneraye, C. Foucher, P. Le Marchant Demande de brevet français 8015 303 (filed 1980). 

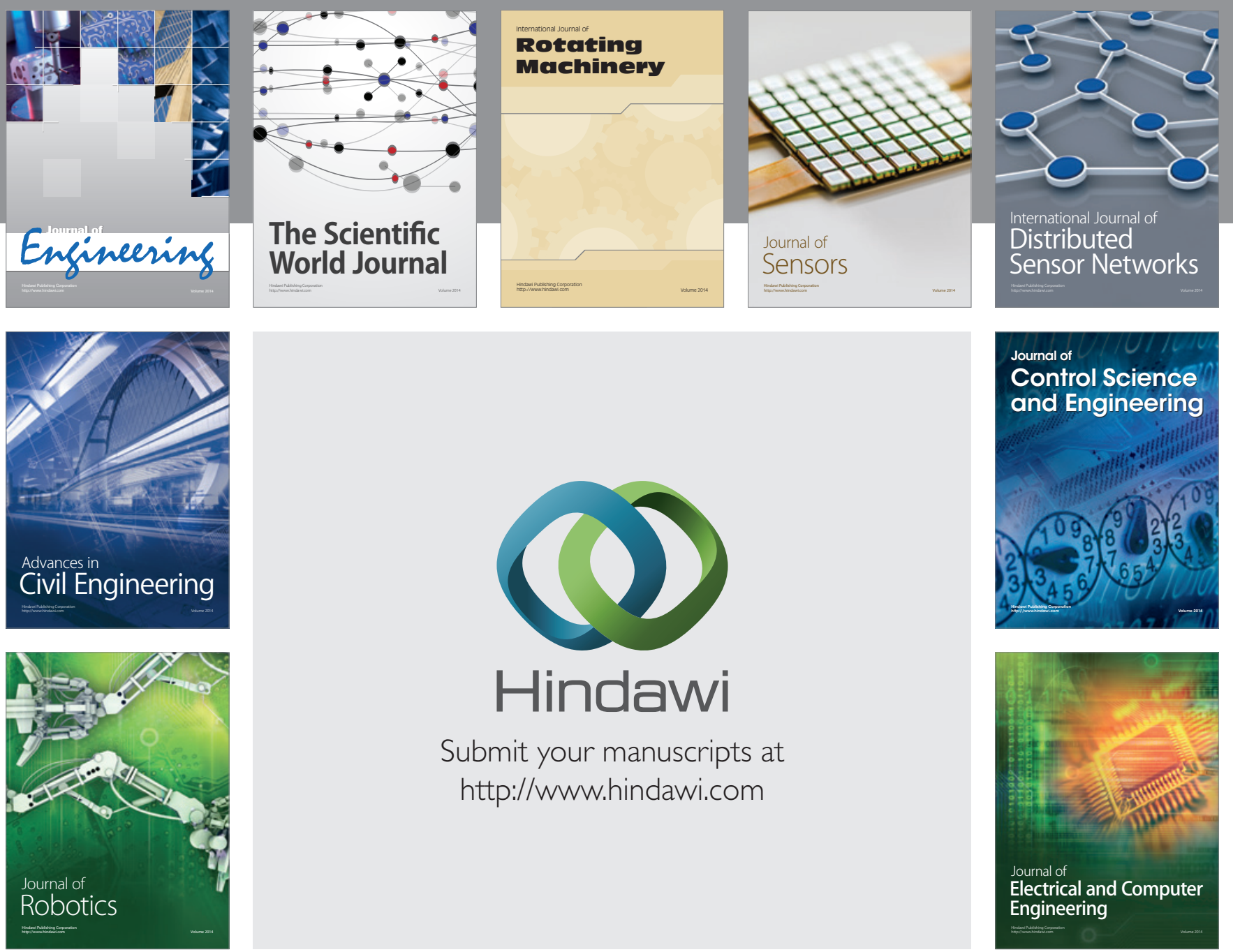

Submit your manuscripts at

http://www.hindawi.com
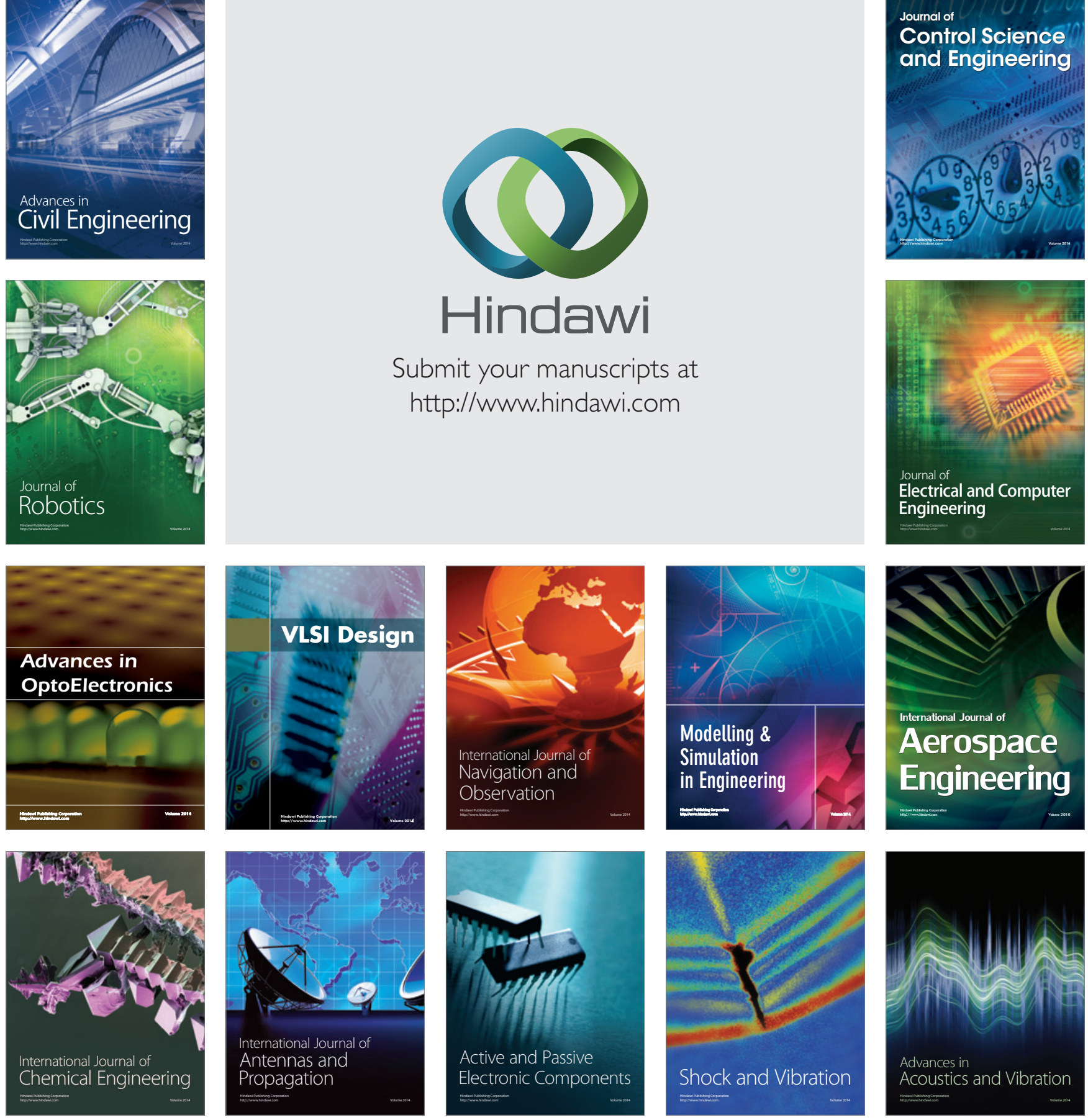